\title{
Some inequalities for geometrically-arithmetically $h$-convex functions
}

\author{
Muhammad Aslam Noor, Khalida Inayat Noor and MuHammad UZair Awan
}

\section{ABSTRACT.}

In this paper, we consider a class of geometrically convex function which is called geometrically-arithmetically $h$-convex function. Some inequalities of Hermite-Hadamard type for geometrically-arithmetically $h$-convex functions are derived. Several special cases are discussed.

Acknowledgement. The authors are grateful to Dr. S. M. Junaid Zaidi, Rector, COMSATS Institute of Information Technology, Pakistan for providing excellent research facilities.

\section{REFERENCES}

[1] Cristescu, G., Hadamard type inequalities for $\varphi$-convex functions, Annals of the University of Oradea, Fascicle of Management and Technological Engineering, CD-Rom Edition, III (XIII), 2004

[2] Cristescu, G., Improved integral inequalities for products of convex functions, J. Inequal. Pure Appl. Math., 6 (2005), No 2, Article 35, 6 pp (electronic)

[3] Cristescu, G. and Lupsa, L., Non-connected Convexities and Applications, Kluwer Academic Publishers, Dordrecht, Holland, 2002

[4] Dragomir, S. S. and Pearce, C. E. M., Selected topics on Hermite-Hadamard inequalities and applications, Victoria University, Australia, 2000

[5] Dragomir, S. S., Pečarić, J. and Persson, L. E., Some inequalities of Hadamard type, Soochow J. Math., 21 (1995), No. 3, 335-341

[6] Dragomir, S. S., Agarwal, R. P. and Cerone, P., On Simpsons inequality and applications, J. Inequal. Appl., 5 (2000), 533-579

[7] Jiang, W.-D., Niu, D.-W., Hua, Y. and Qi, F., Generalizations of Hermite-Hadamard inequality to n-time differentiable functions which are s-convex in the second sense, Analysis (Munich), 32 (2012), No. 3, 209-220

[8] Niculescu, C. P., Convexity according to the geometric mean, Math. Inequal. Appl., 3 (2000), No. 2, 155-167

[9] Noor, M. A., Awan, M. U. and Noor, K. I., On some inequalities for relative semi-convex functions, J. Inequal. Appl., 2013, 2013:332, 16 pp

[10] Noor, M. A., Noor, K. I. and Awan, M. U., Geometrically relative convex functions, Appl. Math. Infor. Sci., 8 (2014), 607-616

[11] Noor, M. A., Qi, F. and Awan, M. U., Some Hermite-Hadamard type inequalities for log-h-convex functions, Analysis (Berlin), 33 (2013), No. 4 , 367-375

[12] Ozdemir, M. E., Tunc, M. and Gurbuz, M., Definitions of h-logaritmic, h-geometric and h-multi convex functions and some inequalities related to them, available online at: arXiv:1211.2750v1 [math.CA]

[13] Shuang, Y., Yin, H.-P. and Qi, F., Hermite-Hadamard type integral inequalities for geometric-arithamatically s-convex functions, Analysis (Berlin), 33 (2013), 197-208

[14] Varosanec, S., On h-convexity, J. Math. Anal. Appl., 326 (2007), No. 1, 303-311

[15] Xi, B.-Y., Wang, S.-H. and Qi, F., Properties and inequalities for the $h$ - and $(h, m)$-logarithmically convex functions, Creat. Math. Inform., 22 (2013)

[16] Zhang, T-Y., Ji, A-P. and Qi, F., On integral inequalities of Hermite-Hadamard type for s-geometrically convex functions, Abstr. Appl. Anal., 2012, Art. ID 560586, 14 pp

[17] Zhang, T-Y., Ji, A-P. and Qi, F., Some inequalities of Hermite-Hadamard type for GA-convex functions with applications to means, Matematiche (Catania), 68 (2013), No. 1, 229-239

[18] Zhang, T-Y., Xi, B.-Y. and Qi, F., Some properties and inequalities for h-geometrically convex functions, J. Classical Anal., 3 (2013), 101-108

DEPARTMENT OF MATHEMATICS

COMSATS INSTITUTE OF INFORMATION TECHNOLOGY

PARK ROAD, ISLAMABAD, PAKISTAN

E-mail address: noormas lamehotmail.com

E-mail address: khalidanoor@hotmail.com

E-mail address: awan.uzair@gmail.com

Received: 04.10.2013; In revised form: 23.11.2013; Accepted: 08.12.2013

2010 Mathematics Subject Classification. 26D15, 26A51.

Key words and phrases. Convex functions, geometrically-arithmetically h-convex functions, Hermite-Hadamard inequality. 